\author{
А.Н. Рутенко, И.Р. Радаев, В.Г. Ущиповский \\ ПРОСТРАНСТВЕННЫЕ ИЗМЕРЕНИЯ ИМПУЛЬСНЫХ \\ АКУСТИЧЕСКИХ СИГНАЛОВ, ГЕНЕРИРУЕМЫХ \\ РАКОМ-ШЕЛКУНОМ В Б. ВИТЯЗЬ ЯПОНСКОГО МОРЯ И \\ РЕЗУЛЬТАТЫ МОДЕЛИРОВАНИЯ ИХ РАСПРОСТРАНЕНИЯ
}

\author{
Тихоокеанский океанологический институт им. В.И. Ильичева ДВО \\ РАН, Россия, 690041, Владивосток, ул. Балтийская, 43, \\ Тел.: (4232) 312120,E-mail: rutenko@poi.dvo.ru
}

\begin{abstract}
Приводятся временные и спектральные характеристики акустического импульсного сигнала, генерируемого на шельфе Японского моря ракомщелкуном. Результаты натурных измерений расширены с помощью согласованного численного моделирования, проведенного с помощью лучевого метода мнимых источников и модового параболического уравнения.
\end{abstract}

Ключевые слова: рак-щелкун, натурные измерения, моделирование

Семейство раков-щелкунов (Alpheidae), включающее более 600 видов, относится к отряду десятиногих ракообразных (decapoda) [1]. Большинство видов раков-щелкунов обитает в тропических и субтропических морях на мелководье, однако некоторые виды живут в прохладных водах. В работах $[3,4]$, представлен анализ акустических сигналов рака-щелкуна, измеренных в Черном море на шельфе Абхазии и в Японском море в заливе Славянка. Характерной особенностью раков-щелкунов является малоподвижный образ жизни, но главная их особенность способность к ультрабыстрому закрытию аномально большой клешни, в результате чего происходит формирование кавитационной высокоскоростной струи воды, которая используется для охоты, обороны, выкапывания норок и коммуникации.

В 2017 г., в бухте Витязь Японского моря, у берега м. Шульца, были измерены редкие высокочастотные 300-24000 Гц акустические импульсы, в которых амплитуда вариаций акустического давления $p(t)$ (см. рис. 1) превысила 3000 Па. Источником таких сигналов мог быть только рак-щелкун. На рис. 1а видно, что амплитуда положительной полуволны в измеренном акустическом импульсе достигла, примерно, 3.2 кПа, это эквивалентно значению уровня 190.1 дБ отн. 1 мкПа. 
На этом рисунке во временной области мы видим «прямой» импульсный сигнал (интервал 1) и сдвинутый по фазе на $180^{\circ}$ сигнал, пришедший в точку приема 0 после отражения от поверхности моря (интервал 2). Толщина водного слоя $H=3$ м. При скорости звука в воде равной $1450 \mathrm{~m} / \mathrm{c}$ и известном времени задержки между «прямым» и отраженным от поверхности моря импульсами, оценим расстояние от «источника» -рака-щелкуна - до измерительного гидрофона. Оно равно 0.7 м.
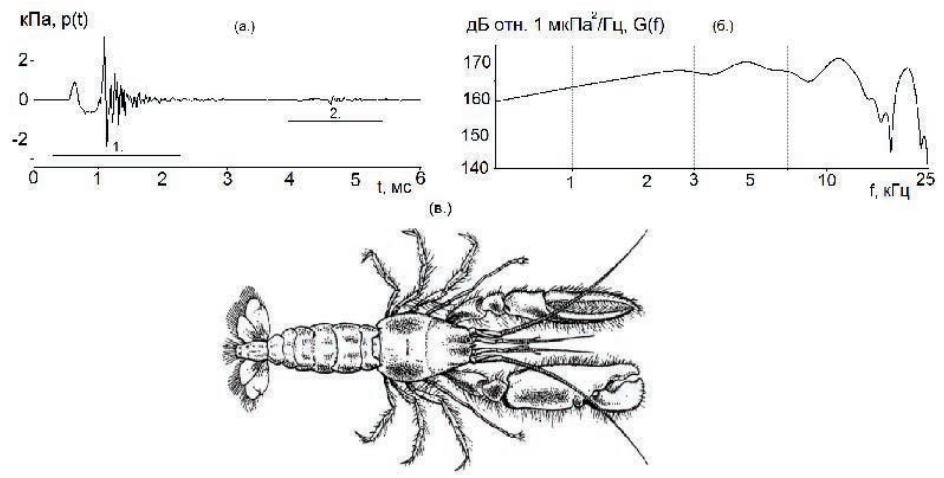

Рис. 1. «Прямой» (интервал 1) и отраженный от поверхности моря (интервал 2) акустические импульсы, излученные раком-щелкуном - (а) и спектр «прямого» сигнала - (б). Рисунок рака-щелкуна Alpheidae - (в).

Для импульса, показанного на рис. 1.: расстояние импульса до его источника меньше глубины $(H=3$ м) водного слоя, поэтому численное моделирование распространения высокочастотного импульса удобно провести с помощью лучевого метода мнимых источников. По акустическому импульсу, измеренному гидрофоном, рассчитывался комплексный спектр, который корректировался с учетом комплексных значений функции потерь, рассчитанных с помощью лучевого метода мнимых источников, при распространении от точки источника $-S$ до гидрофона $-\mathrm{p} 0$. Модифицированный спектр импульса считаем эквивалентной точечной функцией источника. С помощью программы, основанной на лучевом методе мнимых источников, рассчитаем на заданных частотах распространение энергии от данного эквивалентного точечного источника до измерительных гидрофонов р0 и р2, а затем с помощью обратного преобразования Фурье получим временные ряды значений $p(t)$ для p0 и р2, которые показаны на рис. 2. 

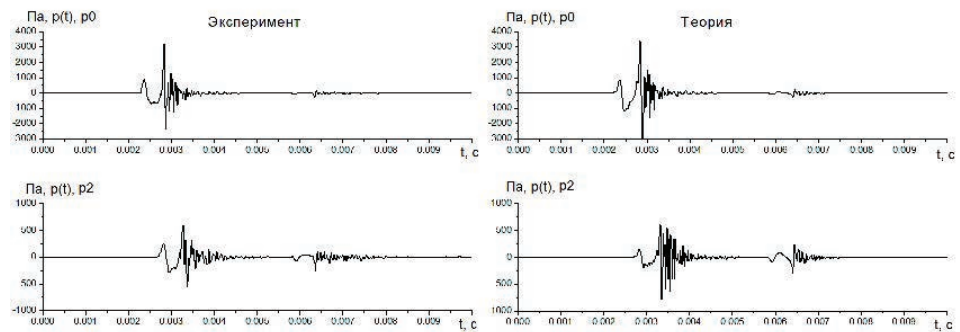

Рис. 2

В докладе приводятся результаты специальных пространственных акустических измерений, проведенных с помощью металлических конструкций, позволивших установить в море глубиной 3 м четыре однотипных гидрофона внутри тетраэдра, а также в виде горизонтальной и вертикальной антенны с апертурой равной 240 см (см. рис. 3). Результаты измерений обобщены и расширены с помощью численного моделирования, результаты которого согласуются с натурными данными.

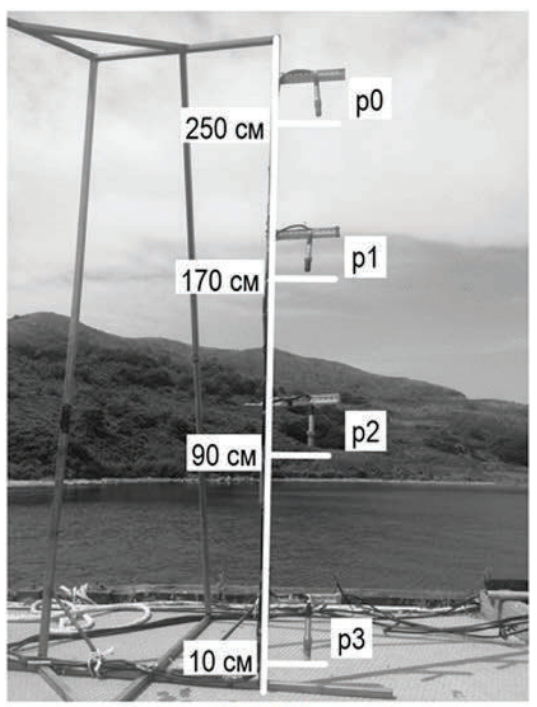

Рис. 3.

Четыре цифровых гидрофона типа ГИ-50 и измерительнорегистрационный комплекс на основе 4-х канального 24 разрядного АЦП NI 9239 компании National Instruments, работающего с частотой дискретизации равной 48 кГц, обеспечили синхронные измерения вариаций акустического давления $-p(t)$ в частотном диапазоне 2-24000 Гц.

Известно, что акустический импульс, формируемый раком-щелкуном имеет диаграмму направленности. С помощью вертикальной акустической антенны, показанной на рис. 3 , установленной в море на глубину 3 м, получены синхронные графики вариаций акустического давления, представленные на рис. 4a. Максимальные амплитуды вариаций $p(t)$, соответствующие прямому и отраженному от поверхности моря импульсам, измерены гидрофоном p1 на расстоянии 170 см от дна. Отметим, что амплитуда прямого сигнала меньше амплитуды сигнала, отраженного от поверхности моря, и это особенно хорошо видно в сигнале, измеренном у дна гидрофоном p3. 
Несложная геометрическая схема позволяет по относительным временным задержкам, представленным на рис. 4a, определить радиус $r$ окружности с вертикальной антенной в центре, на котором находился рак, излучивший акустический импульс, показанный на рис. 4а. Расчеты, выполненные для однородного водного слоя толщиной 3 м и $\mathrm{CW}=1450$ м/с, показали, что в данном случае $r=5.6$ м.

Известно, что рак-щелкун может излучать акустические импульсы

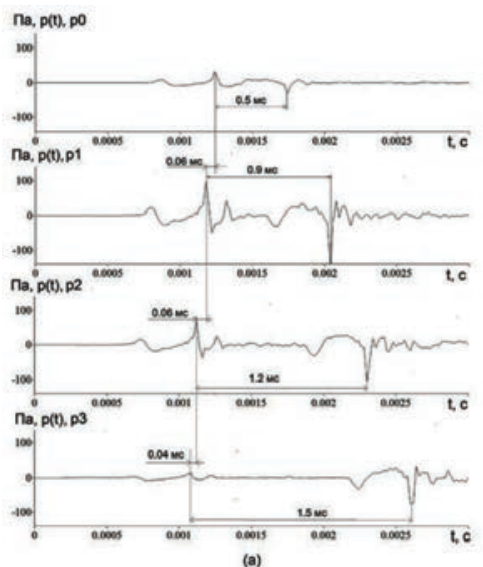

(a)

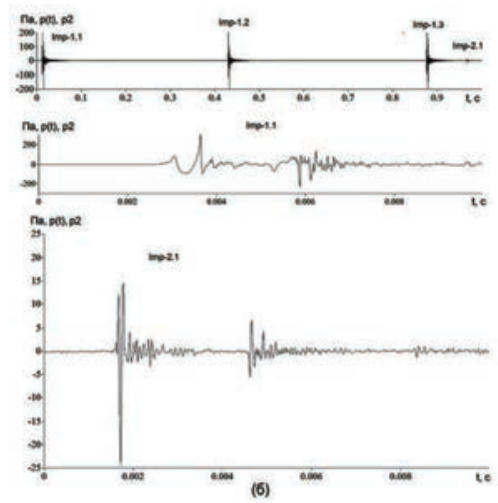

б

Рис. 4. Акустические импульсы, измеренные вертикальной цепочкой из 4 гидрофонов - а; коммуникационный сигнал из 3 импульсов и отклик другого рака - б.

с временным интервалом 0.5 с. На рис. 4 показана тройка импульсов, следующих с периодом 0.4 с. На рис. 4 видно, что параметры этих импульсов подобны во временной области, поэтому мы считаем, что их сгенерировал один и тот же рак-щелкун. Эти тройки могут быть объединены в посылку из 12 импульсов, причем временной интервал между

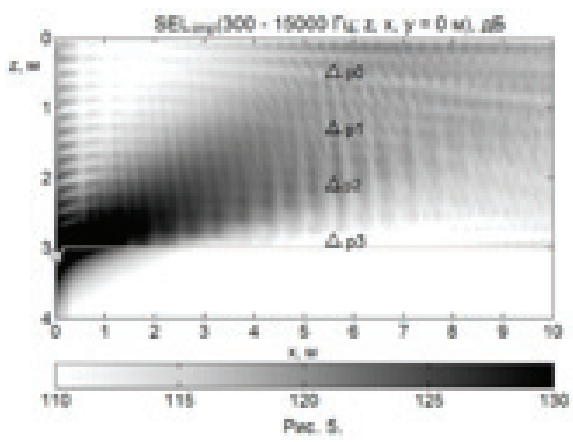
тройками $\Delta \mathrm{T}=1 \mathrm{c}$. Вряд ли он связан с эхолокацией, тогда остается предположить, что это коммуникационные сигналы между разными раками-щелкунами. На рис. 4 в видно, что после 3 импульса рака-щелкуна, гидрофон записал импульс от другого рака-щелкуна - Imp-2.1. Ниже этот сигнал показан более подробно. 
На рис. 5 показано распределение в вертикальной плоскости модельных значений $S E L_{\text {imp }}(300-15000$ Гц; $z, x, y=0)$, рассчитанных с помощью модового параболического уравнения в приближении первых 18 невзаимодействующих вертикальных мод и узкоугольного параболического уравнения в горизонтальной плоскости, для «жидкого» дна [2]. Результаты моделирования хорошо согласуются с натурными данными.

\title{
Литература
}

1. Виноградов Л.Г. Определитель креветок, раков и крабов Дальнего Востока // Известия Тихоокеанского научно-исследовательского института рыбного хозяйства и океанографии. Владивосток. 1950. Т. 33. С. 179-356.

2. Trofimov M.Y., Kozitskiy S.B., Zakharenko A.D. A mode parabolic equation method in the case of the resonant mode interaction // Wave Motion. 2015. Vol. 58. P. 42-52.

\author{
A.N. Rutenko, Iv.R. Radaev, V.G. Ushchipovskii
}

\section{SPATIAL MEASUREMENTS OF PULSE ACOUSTIC SIGNALS GENERATED BY SNAPPING SHRIMP IN VITYAZ BAY OF THE JAPANESE SEA AND RESULTS MODELING THEIR DISTRIBUTION}

\author{
Pacific Oceanological Institute of Far Eastern Branch of Russian Academy of Sciences \\ of V.I. Il ichev, Vladivostok, Russia \\ Tel.: (4232) 312120; E-mail: rutenko@poi.dvo.ru
}

The report shows the temporal and spectral characteristics of the acoustic pulse signal generated on the shelf of the Japanese Sea by the snapping shrimp. The results of field measurements are expanded using a consistent numerical simulation carried out using the ray method of imaginary sources and the parabolic mode equation.

Keywords: snapping shrimp, field measurements, simulation.

\section{References}

1. Vinogradov L.G. Identifier to shrimp, crayfish and crabs of the Far East. Proceedings of the Pacific Research Institute of Fisheries and Oceanography, Vladivostok, 1950, Vol. 33, pp. 179-356.

2. Trofimov M.Y., Kozitskiy S.B., and Zakharenko A.D. A mode parabolic equation method in the case of the resonant mode interaction. Wave Motion, 2015, Vol. 58, pp. 42-52. 